\title{
Microradiography of Otoliths and Vertebral Centra in the Flatfish Limanda herzensteini: Hypermineralization in the Hyaline Zones
}

\author{
Yasuo MugiYa,* Shigeyoshi Hirabayashi, ${ }^{*}$ and Teruaki Ohsawa*
}

(Accepted July 9, 1984)

\begin{abstract}
The otolith and vertebral centrum of the flatfish Limanda herzensteini were microradiographed to find differences in mineral density between the hayline and opaque zones. In the opaque zone of the otolith, the lamellated structure was well developed and appeared as several thick bands of dark brown. The interlamellar spaces contained some material which appeared light brownish under transmitted light. In the hyaline zone, however, the thick lamellae marked by the brown bands were not noticeable and instead thin lamellae containing little brownish material in the interlamellar spaces could be discerned. The thick lamellae showed the highest X-ray permeability and next came the brownish spaces between the lamellae of the opaque zone. Although the thin lamellae were slightly radiolucent, the hyaline zone showed the lowest $\mathrm{X}$-ray permeability as a whole. High radiolucency was also observed in the central area of the otolith, which had a well-developed lamellated structure. In the centrum, the hyaline and opaque zones consisted of an assembly of lower-order opaque and hyaline layers, which were predominant in the respective zones. Microradiographs showed the opaque to be more radiolucent than the hyaline layers, indicating that as a whole the hyaline zone is more compact than the opaque zone. In conclusion, the otolith and the vertebral centrum showed the identical characteristic of having a higher degree of mineralization in the hyaline zones than in the opaque zones.
\end{abstract}

Otoliths and bone have been used for age determination in various fish, because they have annuli consisting of hyaline and opaque zones. The morphological and histochemical natures of these zones have been studied by several researchers, ${ }^{1-8}$ ) but the results do not always coincide concerning which zone is calcium and which is matrix dominated.

In the present study, the otolith and vertebral centrum of flatfish were microradiographed to find differences in mineral density between the hyaline and opaque zones.

\section{Material and Methods}

Most of the flatfish Limanda herzensteini were collected from Funka Bay, Hokkaido, but a small number were obtained from a fish market.

A pair of otoliths (sagittae) were dissected out, washed in water and kept in glycerin for 1-2 weeks until use. A few centra between the 10 th and 20th vertebrae were taken out, separated from the soft tissues under a binocular microscope, and kept in $70 \%$ ethyl alcohol.

Each otolith was embedded in a mass of epoxy resin (Bond E, Konishi Co., Ltd.) on a glass microscope slide and ground by hand with a whetstone to the mid-transverse plane, parallel to the long or short axis, and then polished with the compound whetting paste used for sharpening microtome knives. When the center was reached, the otolith was taken off the slide, then attached to the slide inside out with glue (Aron Alpha, Konishi, Co., Ltd.), and ground and polished again down to a minimum of $50 \mu \mathrm{m}$ in thickness. The ground section was carefully removed from the slide by use of acetone, and cleaned in xylene. The thickness of the section was occasionally measured with a dial thickness gauge (Ozaki Co., Ltd.).

The vertebral centrum was dehydrated through a series of ethyl alcohol solutions up to $100 \%$, and embedded in a mass of methacrylate of suitable hardness (a mixture of 7 parts of $n$-buthylmethacrylate and 3 parts of methacrylate containing benzoyl peroxide of $1.5-1.7 \%$ ). The centrum was longitudinally ground down to $50 \mu \mathrm{m}$ in thickness through the center, parallel to the body axis of the fish.

Microradiography (Sofron-40M, Soken Co., Ltd.) was performed under the following conditions, varying by the specimen and its thickness:

* Faculty of Fisheries, Hokkaido University, Minato-3, Hakodate 041, Japan (麦谷浆雄・职林重義・大沢 照昭：北海道大学水産学部). 
for otoliths, voltage $11-15 \mathrm{kVp}$, current $5 \mathrm{~mA}$, and exposure time $28-130 \mathrm{~min}$; for centra, 8-10 kVp, $5 \mathrm{~mA}$, and $10-35 \mathrm{~min}$. The contact microradiographs were photographed with Vanox (Olympus Co., Ltd.) and printed for observation.

\section{Results}

The otolith of the present fish clearly showed an alternating pattern of hyaline (dark) and opaque (light) zones with an opaque central area under reflected light on a black background (Fig. 1). When the otolith was cut through the center transversely to the long axis, the zonate pattern became more distinct (Figs. 2 and 3), and its detailed structure could be seen especially well under transmitted light (Fig. 3). In the photograph, the hyaline and opaque zones appear light and dark, respectively, which is different from the zonate image under reflected light (Fig. 2). The opaque zone was characterized by the presence of

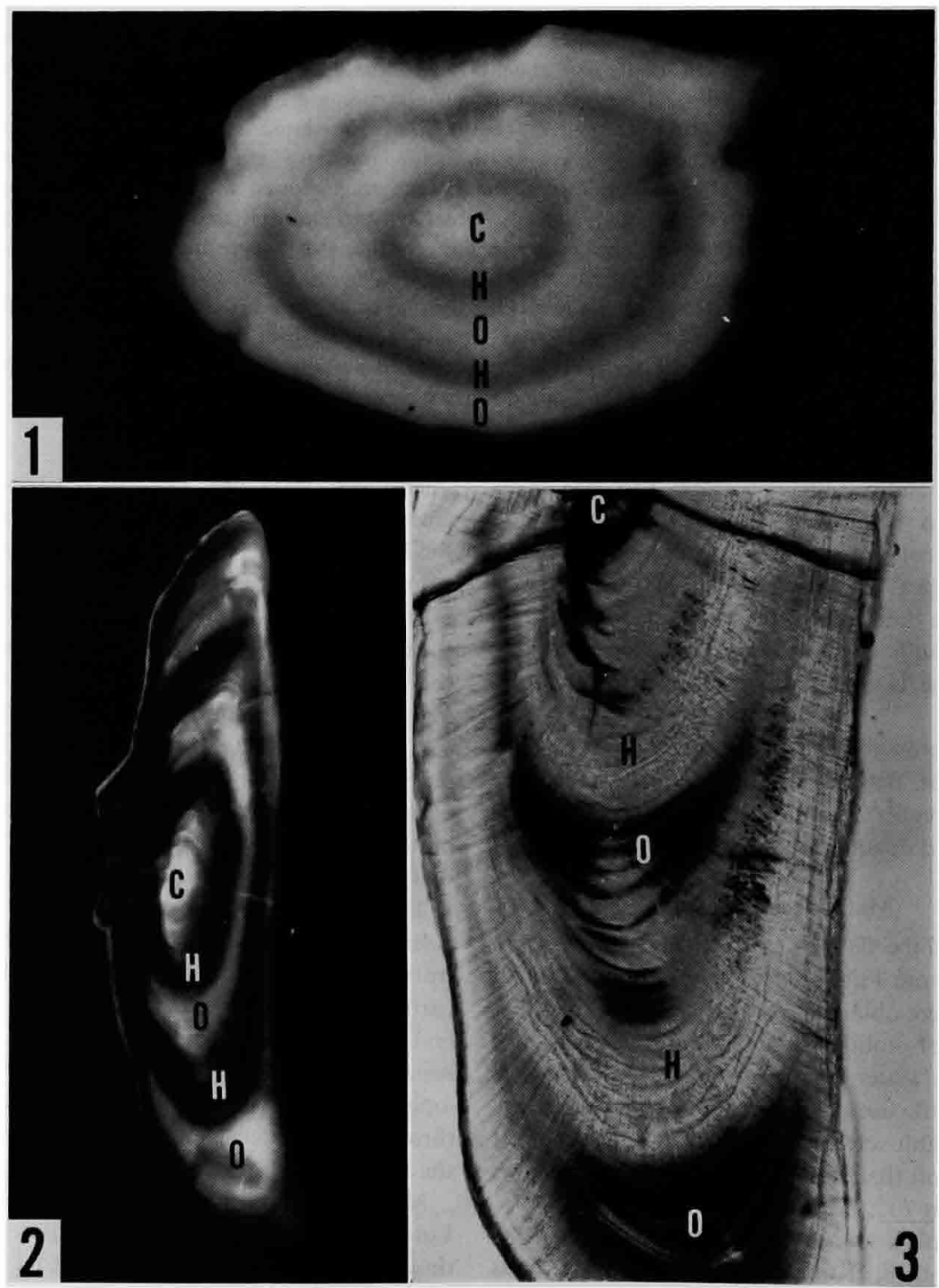

Figs. 1-3. An otolith of flatfish. $\mathrm{C}$ : central area; $\mathrm{H}$ : hyaline zone; $\mathrm{O}$ : opaque zone. 1 . Surface view under reflected light. 2. Transverse section of the same otolith. Reflected light. 3. Higher magnification of the section. Transmitted light. 
several thick lamellae which ran concentrically and appeared dark brown (Fig. 3). The interlamellar spaces also usually appeared light brownish and occasionally contained lower-order fine lamellae (Fig. 6). In the hyaline zone, however, the thick lamellae were not marked, and only poorly developed thin lamellae could be discerned (Fig. 3). Little brownish material was contained in this zone. The central area showed a welldeveloped lamellated structure, appearing opaque under reflected light (Fig. 2). Needle-like crystals of calcium carbonate with the intercrystalline matrix radiated from the center to the margin through the hyaline and opaque zones (Fig. 3).

As the otolith is a highly calcified tissue, soft $\mathrm{X}$-ray penetration is not enough to obtain a micro-

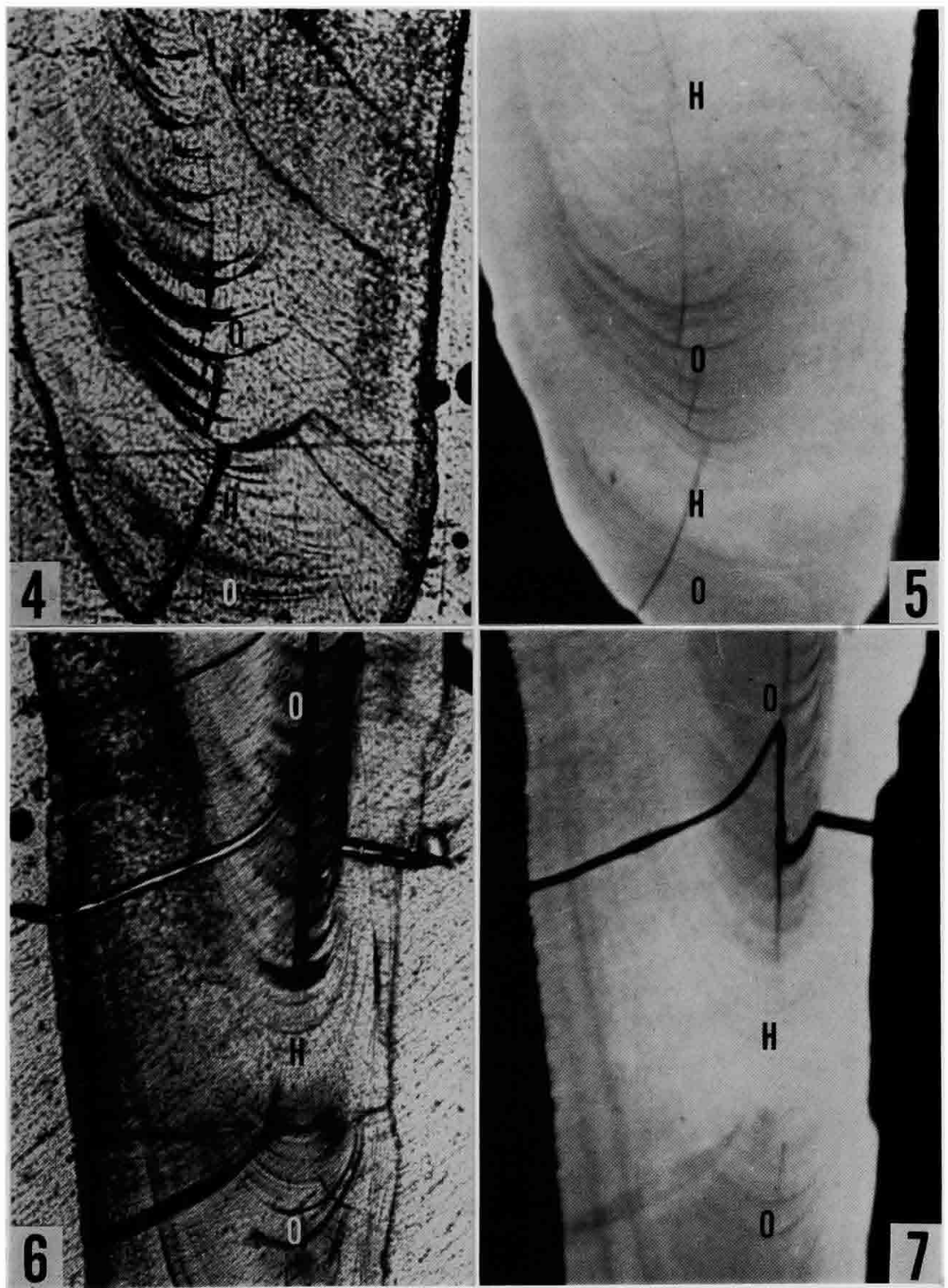

Figs. 4-7. Transverse and longitudinal sections of flatfish otoliths. $\mathrm{H}$ : hyaline zone; $\mathrm{O}$ : opaque zone. 4. Transverse section under transmitted light. 5. Microradiograph of the same section (voltage $12 \mathrm{kVp}$, current $5 \mathrm{~mA}$, exposure time $130 \mathrm{~min}$ ). 6. Longitudinal section under transmitted light. 7. Microradiograph of the longitudinal section (12 kVp, $5 \mathrm{~mA}, 130 \mathrm{~min})$. 
radiographic image unless a thin section is exposed for a long time. In addition, the microradiographs obtained usually do not show a distinct contrast between the opaque and hyaline zones because of a small difference in radiodensity between the zones. However, they tell us about some important aspects of mineral distribution in the otolith. In a correlated photomicrographic and microradiographic investigation of the transverse (Figs. 4 and 5) or longitudinal (Figs. 6 and 7) section, the thick lamellae in the opaque zone showed the highest $\mathrm{X}$-ray permeability and next came the brownish area between the lamellae. The radiographic pattern of the lower-order lamellae in this area was not marked under the present conditions. Although the thin lamellae in the hyaline zone were slightly radiolucent, this zone had the lowest permeability as a whole (Figs. 5 and 7), indicating that the hyaline zone is more highly calcified than the opaque zone in the otolith. These results suggest that the thick and thin lamellae are organic in nature and that the interlamellar spaces in the opaque zone contain a relatively large amount of organic matrix. Crystal prints running radially were not visible in the microradiographs.

The central area of a transverse otolith was half circled by an opaque band, when observed under reflected light (Fig. 8). In a higher magnification under transmitted light, the band consisted of several well-developed lamellae (Fig. 9). The microradiograph of the same section showed that each lamella had low mineral density and therefore the opaque band appeared as a radiolucent band on the X-ray image (Fig. 10). The core of the central area also had a radiolucent nature.

The vertebral centrum showed opaque and hyaline zones on its inner surface, when observed under reflected light. Each zone consisted of an assembly of lower-order opaque and hyaline layers (Fig. 11), and these layers were predominant in the respective zones. In the thin section of the centrum, which was photographed under transmitted light, the hyaline and opaque layers corresponded to light and dark ones, respectively (Fig. 12). In the microradiograph of the same section, the light layers were obviously more radiopaque than the dark layers (Fig. 13), indicating that
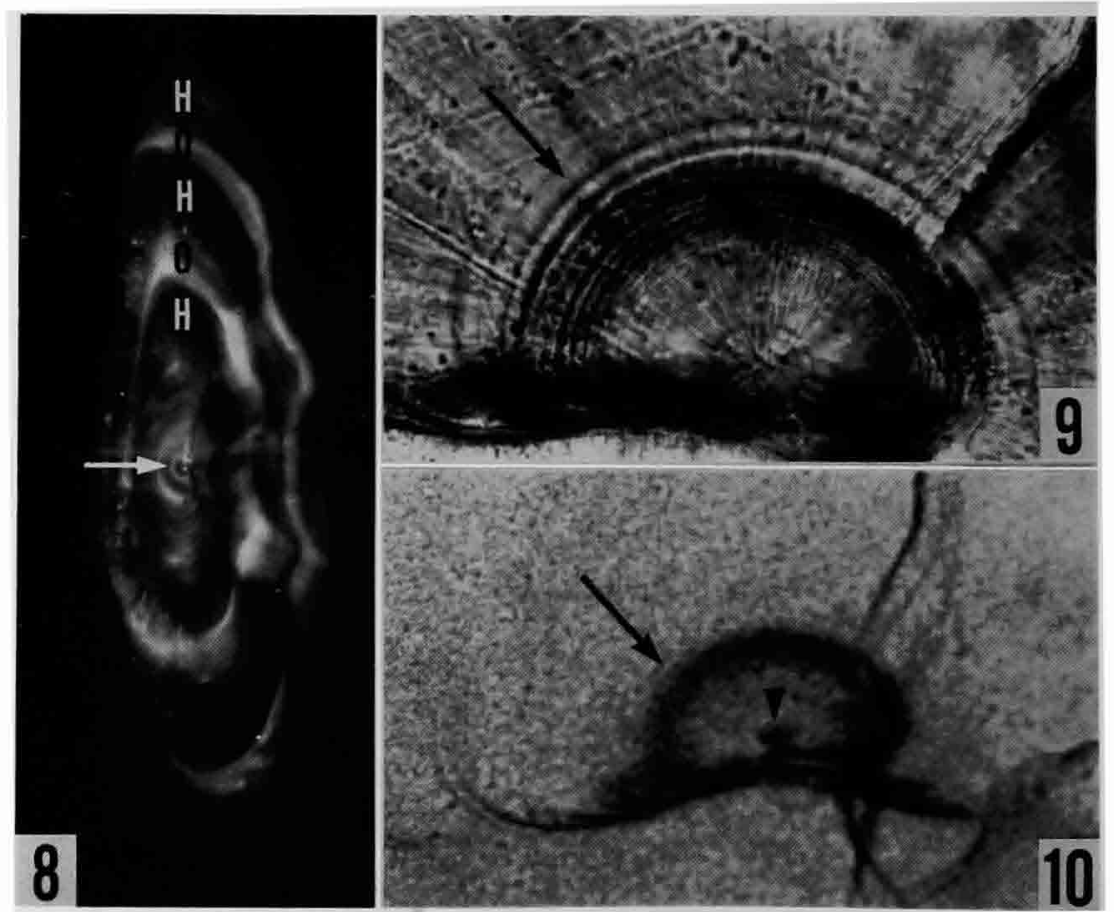

Figs. 8-10. An otolith of flatfish. Arrows indicate the central area. 8. Transverse section of the otolith under reflected light. $\mathrm{H}$ : hyaline zone; $\mathrm{O}$ : opaque zone. 9. Central area of the same section under transmitted light. 10. Microradiograph of the central area with the core (arrowhead) (15 kVp, $5 \mathrm{~mA}, 28 \mathrm{~min})$. 


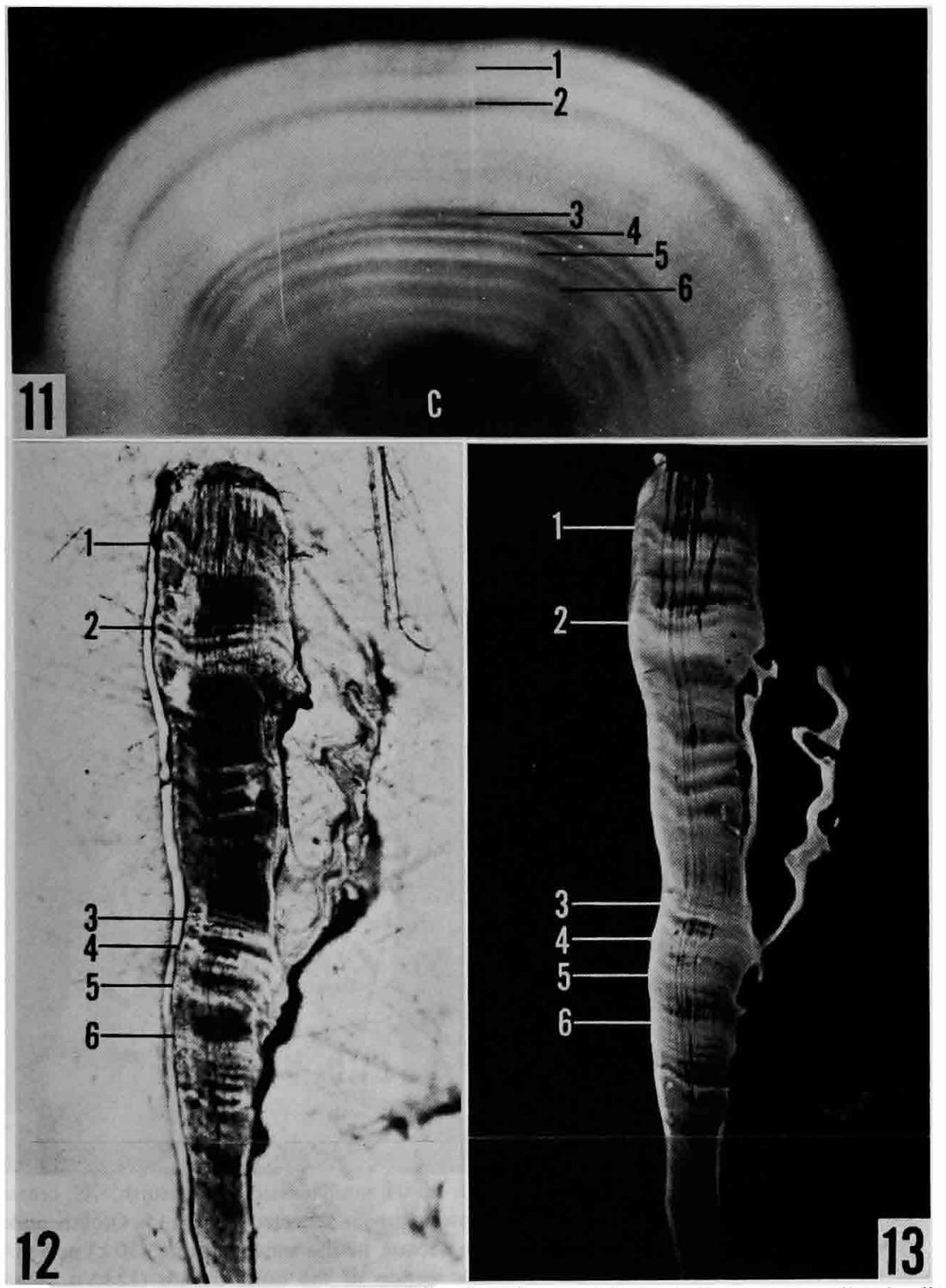

Figs. 11-13. A vertebral centrum of flatfish. Numbers 1-6 indicate the corresponding hyaline layers in each figure. 11. Half of the centrum, under reflected light. C: center. 12. Thin section of the same centrum. Transmitted light. 13. Microradiograph of the same section (10 kVp, $5 \mathrm{~mA}, 28 \mathrm{~min}$ ).

hypermineralization occurs in the hyaline zone as a whole.

The mineral density of opaque and hyaline zones was compared between the centrum and otolith of the same individual. They had two hyaline zones on each of their surfaces, and appeared to be in a stage of transit between opaque and hyaline zone formation (Figs. 14 and 15). Microradio- graphs of these specimens revealed that the opaque zones had a higher X-ray permeability than the hyaline zones in both tissues (Figs. 16 and 17). These results suggest that hypermineralization causes a zone to be optically hyaline, irrespective of the wide differences in crystal type and calcium content between the centrum and the otolith. 


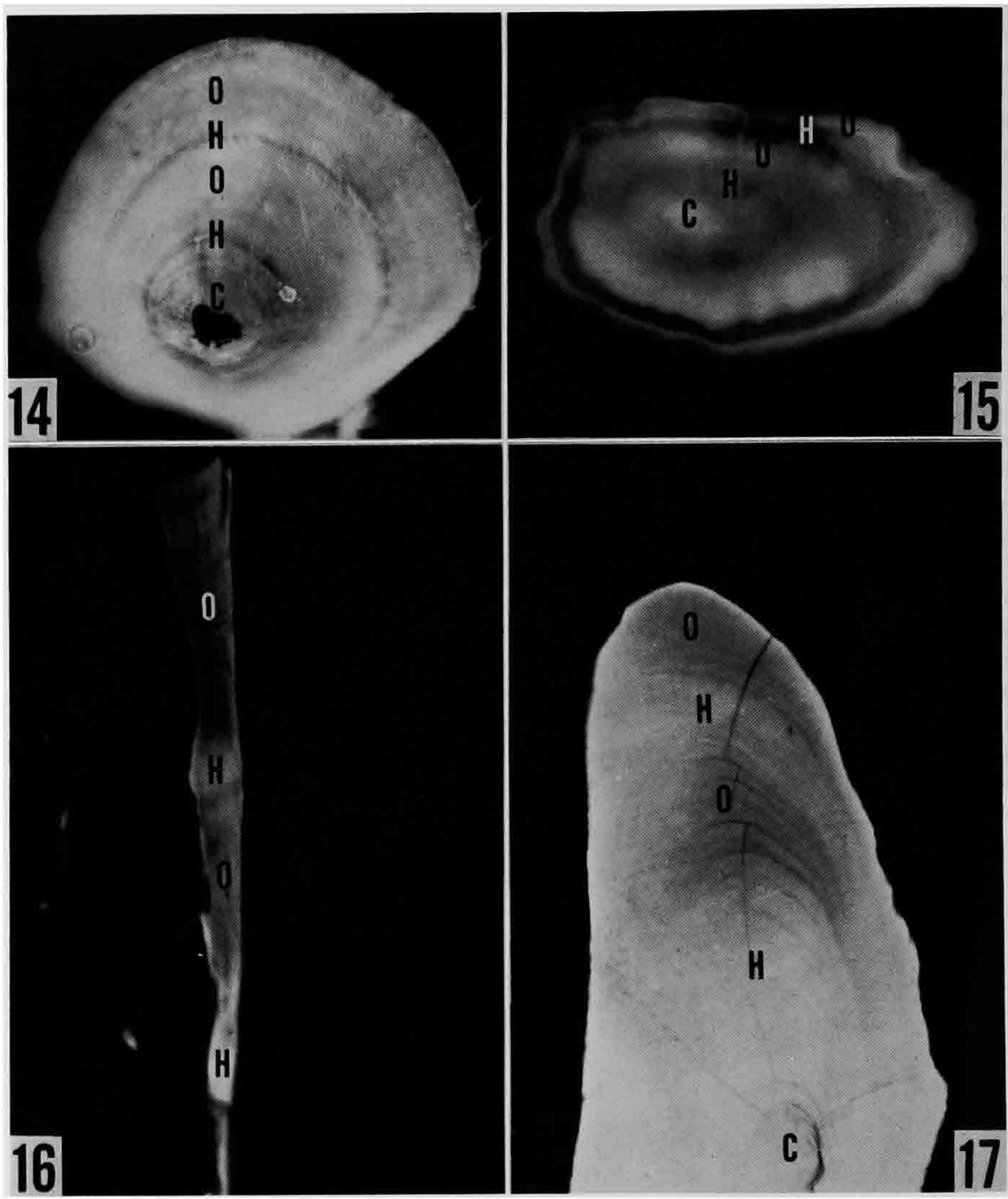

Figs. 14-17. A vertebral centrum and an otolith from the same individual of flatfish. C: center; $\mathrm{H}$ : hyaline zone; $\mathrm{O}$ : opaque zone. 14. Centrum under reflected light. 15. Otolith under reflected light. 16. Microradiograph of thin section of the same centrum $(10 \mathrm{kVp}, 5 \mathrm{~mA}$, $35 \mathrm{~min})$. 17. Microradiograph of transverse section of the same otolith $(12 \mathrm{kVp}, 5 \mathrm{~mA}$, $130 \mathrm{~min})$.

\section{Discussion}

There has been controversy concerning the chemical and crystallographical differences between the hyaline and opaque zones of fish otoliths. BLACKER $^{7)}$ reviewed this matter, and concluded that the hyaline zone contained less calcium and more organic matter than the opaque zone, when a unit volume of material was compared. However, the present $\mathrm{X}$-ray study indicates a higher degree of radiolucency in the opaque zone than in the hyaline zone, irrespective of whether the sections were cut in a transverse or longitudinal direction. This fact excludes the possibility that a difference in orientation of calcium crystals caused the X-ray permeability of the hyaline and opaque zones to be different. In fact, needlelike crystals of calcium carbonate were morphologically observed running through the hyaline and opaque zones in the same radial direction. As 
mineral density appears to be essentially responsible for the X-ray permeability of the otolith, the present results indicate that hypermineralization occurs not in the opaque but in the hyaline zone.

In a histological observation of the vertebral centrum of flatfish, KUSAKARI ${ }^{\text {s) }}$ found that the opaque zone was deeply stained with hematoxylin, whereas the hyaline zone was stained with eosin, and concluded that the opaque zone was more highly calcified than the hyaline zone. More recently, however, CASSELMAN ${ }^{8)}$ examined the bone (cleithrum) of pike by an electron microprobe $\mathrm{X}$ ray analyser and confirmed that calcium was uniformly high in the hyaline zone but was lower and more variable in the opaque zone. In the centrum of the present fish, microradiographs revealed clearly that the opaque zone was more radiolucent than the hyaline zone, indicative of low and high degrees of mineralization in the opaque and hyaline zones, respectively.

Although the otolith and the centrum are very different from each other in mineral type, content and metabolism, ${ }^{0)}$ their hyaline zones are characterized by a similarity in having high radiodensity. In the present fish, the hyaline zones of both tissues were formed once a year from fall to early spring, when the body growth of the fish stagnated.* Therefore, a slowdown in appositional tissue growth due to a possible reduction in matrix formation might result in high mineral density and thereby make the "winter zones" optically hyaline in the otolith and the bone. A similar case has been reported in the teeth of some mammals: A highly calcified zone is formed as a result of growth stagnation in winter and the zone usually appears as hyaline. ${ }^{10)}$ Translucent zones due to high mineralization are also known to occur in the carious lesion of enamel ${ }^{11}$ and in the shell of molluscs. ${ }^{12)}$

\section{References}

1) C. F. Hickling: Quart. J. Micr. Sci., 74, 547561 (1931).

2) T. IRIE: J. Fac. Fish. Anim. Husb. Hiroshima Univ., 3, 203-221 (1960).

3) S. W. Sмiтh: J. Cons. Perm. Int. Explor. Mer, 32, 270-277 (1968).

4) M. Kusakari: Bull. Japan. Soc. Sci. Fish., 35, 7-17 (1969).

5) T. FuruI: Bull. Hakodate Ohtani Wom. Jr. Col., (4), 1-12 (1971).

๑) G. Pennella: in "Ageing of Fish" (ed. by T. B. BegenaL), Unwin Brothers, Old Woking, 1974, pp. 28-39.

7) R. W. BLACKer: J. Cons. Perm. Int. Explor. Mer, 33, 107-108 (1969).

8) J. M. Casselman: in "Ageing of Fish" (ed. by T. B. Begenal), Unwin Brothers, Old Woking, 1974, pp. 13-27.

9) T. IchII and Y. MugrYa: Bull. Japan. Soc. Sci. Fish., 49, 1039-1044 (1983).

10) N. Ohtaishi: Mammal. Sci., (34), 1-7 (1977).

11) J. Kostlán: Brit. Dent. J., 113, 244-248 (1962).

12) I. KobayasHi: Mar. Sci., 5, 768-773 (1973).

* Unpublished data. 